\title{
Make in India: Fast Track Road to Inclusive and \\ MIAKE IN \\ INDIA Sustainable Growth
}

Wuplow

\author{
Author: Ishwar C. Dhingra \\ Publisher: Cosmos Bookhive Gurgaon \\ Price: 150
}

\section{*VishnumoorthyPrabhu}

Make in India is a buzz word now. If you look at the bewilderingly vast number of articles and literary output on the subject, you would be lost. But if you are looking for a simple book on the subject with a layman's approach, you may not find many. Though you may be fortunate to find a few, reading through, you would realise that you are not that fortunate!

The book "Make in India: Fast Track Road to Inclusive and Sustainable Growth" by Ishwar c. Dhingra is one more addition to the host of literature you would find on the subject. Unlike many other books on the subject, this book does not deal with too much of technical analysis and data. It's an introductory book that presents the saga of a county with colonial heritage, in the midst of global economic upheaval and the drastic polices to liberalise and set the economy in the path of progress.

The book uses a dialogic method with some participants of a seminar discussing issues with Sabina, the month piece of the author. The technique is often preferred for its focussed treatment of the subject. However, this book fails to provide a focussed discussion on the topic as it meanders from one aspect to the other quite easily.

The book presents the arguments for "make in India" not as "a political scheme but as a comprehensive philosophy of growth that suits the newly emerging economics". The case is presented in the form of an annual memorial lecture in honour of Prof. Paul samuelson by Dr. Sabina, a liberal Muslim lady.This again, is an interesting strategy by the author who also speculates how the ruling and the opposition parties look forward to the lecture. The strategy if used in a modest way, would have presented an opportunity for the

*Assistant Professor, Department of English, G.F.G. CHebri 
writer to present a balanced view of the "Make in India" initiative.

In the form of a dialogue between the participants and Sabina, the author takes up important issues such as Global recession, GrExit and the policies of IMF. In support of her argument for Make in India, the speaker provides evidences from a wide range of sources from the former governor of RBI Mr RaghuramRajan's speech to prime ministers tweet and remarks. The book also traces the journey of Make in India form a slogan to a policy. Various initiatives to transform 'Make in India' into "a philosophy of growth, mission and strategy to create sustained, inclusive and rapid growth" are discussed in considerable detail. The book also takes into consideration the effect of raising inflation on CPI, the stalled infrastructure projects, bureaucratic red tapism and truncated government expenditure on existing projects. The book takes into consideration The Macro Economic Picture and gives a reality check to media-hyped propaganda of'Make in India'.

Taking up the discussion of weather 'Make in India' dilutes the policy-emphasis on the growth of service sector, the book refers to a complimentary program by government called 'served from India'.

The simple style in which the book is written and the comprehensive approach makes this book handy and useful for an under graduate student. However, the very approach is also a limitation of the book. In a bid to provide fascinating information, the book includes jingles rhymes, extracts from newspaper and WhatsApp jokes. This attention-grabbing tactic leads the author even to encrypt a Chinese proverb in Chinese language. This leads a serious reader astray and a serious point slip out of his notice.

Undergraduate students can go for this book for an understanding of comprehensive economic scenario in which the project of 'Make in India' has kick started. However, the lack of clear cut vision and in depth analysis at a micro level prove to be serious limitations of the book. 